\title{
Research on the English Terminology Translation and Practical Teaching in Cognitive Perspective
}

\author{
Jialei Cao \\ School of Foreign Languages, Changchun University of Science and Technology, Changchun, 130022, \\ China
}

Keywords: Cognitive Linguistics, Terminology, Translation Strategies, Terminology Library

\begin{abstract}
This paper starts from the study of cognitive linguistics, explores the principles and methods of translation of English terminology, reveals the close relationship between terminology and translatology, and solves the problem in translation process of English majors in different fields through the practical teaching of terminology translation.
\end{abstract}

\section{Views on the Translation of Cognitive Linguistics}

The basic view of cognitive linguistics can be summed up as "reality - cognition - language", that is, between the reality and the language of "cognitive" this intermediate link. From the direction of language formation, people based on the interactive experience of the objective external, through the formation of cognitive processing language, reality before the cognitive, cognitive before the language, language is the product of reality and cognition, the language behind the human Cognitive language and the law of the objective world, no wonder cognitive linguists to raise the language similarity (language expression and reality / cognitive there is a lot of legitimacy between); if from the perspective of language translation, The interactive interaction of the cognitive subject (including the author, the reader and the translator) is the basis of cognition. The reader and the translator understand the various meanings expressed in the source language as far as possible in the target language to express it in the translation should focus on the author to describe the real world and the cognitive world. Therefore, it is not only necessary to take into account the author, but also the works themselves, and the readers should be taken into account, depending on the three links (authors, texts, readers) in the communication procedure. Only the three elements of the process of communication closely together, taking full account of the experience and understanding of the two elements of the constraints, and strive to deal with the interaction between several people, so as to better understand the author, understand the work, Translation of the text, in order to achieve the "rationality of interpretation" and "translation of harmony." This is the cognitive linguistic translation concept, or called the cognitive linguistic model of translation.

\section{The Principles and Methods of Terminology Translation}

The advancement of modern science and technology, the development of social economy, has led to new things being discovered, new theories have been proposed, new concepts have been created, and these concepts need to be spread out by means of the term. In particular, the frequent spread of technology and communication around the world highlights the importance of translation and terminology. Since the mid-20th century, translation and terminology has been developed by leaps and bounds, and gradually gained independent academic status. In order to meet the social and economic development needs, colleges and universities in recent years have set up translation major, to cultivate the much-needed social translation talents. The concept of "term competence" is presented in this context. However, the domestic and foreign scholars for the term competence of the relevant research, more rare, not yet formed a system, the concept of the definition and meaning to be further explored and improved. Therefore, the translation of terminology has become an important subject in the current academic circles, and it is also a very difficult topic in the current 
translation studies.

The correct communication of terminology plays a key role in the technology communication, but the way of expressing the real world in different languages is different. Therefore, the problem of translation of terminology is becoming more and more urgent, which is one of the hotspots of translation research. To solve the problem of translation of the term, the translator must have a good terminology literacy, the terminology work has a certain understanding and mastery, that is, with the terminology. In recent years, China has set up translation of undergraduate and professional master's two stages of education, aimed at the close combination of socio-economic development needs, set up relevant courses, language services industry to develop practical needs, applied talents. The translation of the translator's terminology in translation teaching is necessary and urgent. The National Symposium on Translation-oriented Terminology is held in 2010 and 201 respectively. The purpose of the conference is to study the terminology translation theory, Promote terminology translation practice, prosperity terminology translation career ". It can be seen that the common concern of industry and academia highlights the importance of term translation in applied translation. Due to the need of social and economic development, the translation industry letter requires a large number of outstanding translators who can use the translation work, and the knowledge and skills required to have the translation of the term is the necessary capacity for these translators.

Terminology translation studies can be divided into: foreign language translation of foreign terminology and translation of Chinese terminology. Many advanced modern technical knowledge and experience are derived from the Western world, the language is mainly English. Therefore, the direction of science and technology translation is mainly from foreign language into Chinese. In the translation of terminology, we need to understand the characteristics of the terminology first, and carry on the thorough research on the morphological and semantic level. Uniqueness, accuracy, conciseness, stability, systematic, emotional color neutrality is the core feature of the term, in order to do the translation of the term, must firmly follow these characteristics.

The lexical level of foreign terminology is mainly reflected in the discussion of the way of word formation. In accordance with the word formation, foreign terms can be divided into simple words, derived words, compound words, acronyms, phrase terms and so on. The roots of many foreign terms come from Greek and Latin, because Greek and Latin are the basis of Western modern technology, especially in English. Linguists have studied the structural characteristics of the Indo-European terminology, and summed up the six structural methods such as escaping method, synthetic method, transition method, adding method, condensing method and foreign language borrowing method.

The purpose of the term translation is to pass the concept of terminology to the target language reader accurately by using the target vocabulary. Therefore, the semantic analysis of foreign terms is also a necessary part of its translation process. Any term has a literal meaning and an academic meaning. In the study of terminology, linguists should rethink the literal meaning of the term, and professional scientists should focus on the academic meaning of the term. The literal meaning of the term is the basis of its academic meaning. The academic meaning of the term cannot be separated from its literal meaning. The meaning of the subject should be richer than the literal meaning of the term. The academic meaning of the term cannot be related to the term. The literal meaning of the conflict, it can only be on the basis of the literal meaning of the term to further scientific explanation and the formation. Therefore, in the translation of foreign terms, its literal meaning and academic meaning should be equal.

The translation of Chinese terminology mainly involves terminology in the traditional field. In addition to the need to follow the general rules of the translation of the term, we need to conduct a detailed analysis of traditional Chinese terminology, the development of specific and feasible translation principles and methods.

Traditional terminology has a strong national characteristic, in Western languages are generally rarely able to find the right words, noun terms often appear transliteration confusion, translation language length and interpretation of the unknown phenomenon. In this case, linguists put forward 
five basic principles of translation of noun terms, namely natural principle, simplicity principle, national principle, retranslation principle, prescriptive principle, pointed out that literal translation, free translation and transliteration of terminology of the commonly used translation methods, increased the principle of accuracy, the principle of unity, customary principles and academic principles. The translation of the term should not only consider its professional tradition, but also consider the international exchange, that is, the semantic style of equivalence, to retain the convention of translation, transliteration, translation and transliteration and transliteration.

\section{The Practical Teaching of Terminology Translation}

The translation of professional settings is the inevitable trend of Chinese social development, with a clear professional orientation, to the rapid translation of the community's business needs, training in the translation of the urgent need for application, practice and professional translation talent. Therefore, the translation education should be closely linked with the social practice and the actual development of the translation industry, so as to establish the relevant curriculum system and teaching principles, highlighting the students' practical ability and vocational skills, pay attention to the practical curriculum and construction, the application of diversified Teaching mode, to the specific implementation of the idea of translation education, to achieve application-oriented, practical, professional translation of personnel training objectives. Translation teaching should focus on developing students' knowledge and skills needed to develop a translation profession so that students can become translators of a competency at the time of graduation to address the urgent needs of society for translators. In the traditional translation teaching in China, although there is also the focus on the ability to cultivate the focus, which focuses on the language ability and professional ability, but this training model is not complete, the lack of systematic. According to the requirements of social and economic development and translation professionalization in China, it is necessary to set up corresponding teaching objectives, set up targeted teaching contents and implement effective teaching methods so as to construct a training mode that can meet the professional translators' One of the key points in the current teaching reform of college translation is also the technical difficulty that the author needs to solve. Our purpose is to be in the English translation of the professional classroom, will cultivate students the ability to target the teaching objectives of specific and operational. Through the investigation and compilation of information, the paper analyzes the terminology ability of English majors, and finds out the difficult problems in the field of translation of different professional terms such as legal English terminology, scientific English terminology, foreign trade English terminology and information technology English terminology. This paper analyzes the importance of the study of terminology in translation practice and translation research, and reveals the close relationship between terminology and translation in terms of translation principles and methods, translation terminology management, translation-oriented terminology education. We will analyze the terminology competence of professional students, study the characteristics of terminology, semantic components, composition, terminology standardization, terminology translation standardization, terminology translation principles and skills, translator's literacy and other related issues, through the professional Style translation practice, to solve the difficult problems in the field of translator terminology, to train students in the field of expertise in the ability of Chinese and foreign translation, to cultivate the social needs of the terminology with the professional translation of talent.

In order to achieve the above objectives, we intend to complete the translation of the professional language library, terminology and translation knowledge base and other forms of resource library construction. A large number of electronic terminology records should be collected in the termbase, which contains information about the terms and the concepts they represent, such as definitions, context, foreign language equivalence, grammar and usage information, conceptual relationships, and so on. Through the way of school-enterprise cooperation to share translation company accumulated translation memory for students to learn and experience the translation memory in the translation of the role of the term. The above-mentioned various resource pools can be integrated through the information-based teaching platform, the various resource banks stored in the teaching 
platform of the server, students with their own student number and password landing, access and use of various resources. We can through the translation of case teaching, the creation of translation teaching workshops, providing training platform and other forms, in the school English translation professional pilot teaching. The information technology teaching platform is integrated, the construction of related terms resource inventory for the term competence teaching to provide a new model of teacher-student interaction. Finally, in the English translation of the professional classroom, the translator terminology is the teaching objectives of specific and operational. Through the professional style of translation practice, we train students in the field of expertise the ability of Chinese and foreign translation to cultivate the social needs of the terminology with the professional translation of talent. The combination of theory and practice enables students to have the knowledge and skills to deal with terminology in practical translation work and become an excellent translator of applied, practical and professional.

\section{Conclusion}

The translation of terminology in cognitive horizons is the intersection of two disciplines of terminology and translation. The use of theoretical knowledge of terminology as a guide, to better grasp the nature and characteristics of the term, in order to complete the terminology translation of high quality. The terminology of the characteristics, composition and semantic analysis is the basic content of terminology research and scholars have used theoretical knowledge to guide the translation of the principles and methods. With the gradual emergence of terminology in the domestic academic field, more terminology knowledge is applied to the translation of terminology. From the perspective of terminology translation, this paper analyzes how to exert the positive influence of term translation on terminology standardization. From the perspective of terminology construction, it discusses how to promote the standardized translation problem of terminology, and points out that the translator must master and use the terminology knowledge to realize the translation of terms Standardization and standardization, and thus have a positive impact on the standardization of terminology. The relationship between terminology translation and terminology standardization is extremely close and should be mutually reinforcing. Nevertheless, the use of terminology theory in the translation of terms has yet to be further studied. Such as communicative terminology, cognitive terminology, social terminology, framework terminology and other theories, can provide a new perspective for the study of terminology translation.

\section{References}

[1] Zheng Shu spectrum. Term translation and its countermeasures[J]. Foreign Language Journal, $2012(5)$

[2] Friedrich Wenger Riel. Introduction to Cognitive Linguistics[M]. Shanghai: Fudan University Press, 2009.

[3] Li Haibin. Cognitive terminology: the new direction of terminology research [J]. Foreign Language Journal, 2014 (3)

[4] Liang Ailin. On the theoretical basis of cognitive terminology and its application [J] terminology standardization and information technology, 2009 (1)

[5] Meng Lingxia. Terminology translation from the perspective of terminology [J] China Science and Technology Translation, 2011 (2)

[6] Ou Gen Weisi. Ordinary terminology and terminology dictionary Introduction to bibliography[M]. Beijing: Commercial Press, 2011.

[7] I Lin Hai, Shen Huairong. Terminology and Terminology Translation Studies [M] Nanjing: Southeast University Press, 2012.

[8] Song Lei. Translation of legal terms to slightly[M]. Beijing: Beijing University of Political 
Science and Law Press, 2011.

[9] Habitat Hearing. On several English grammatical terminology dialectics[J]. Foreign Language Teaching, 2013

[10] Wang Shao-shuang. Translation professional students' terminology training: experience, status and recommendations [J]. Foreign language, 2013 (5) 